\title{
Complex emergence patterns in a bark beetle predator
}

\author{
John D. Reeve \\ Southern Research Station, USDA forest Service and Shreveport Highway, 2500, Pineville, LA 71360, U.S.A.
}

\begin{abstract}
The emergence pattern of Thanasimus dubius (F.) (Coleoptera: Cleridae), a common predator of the southern pine beetle, Dendroctonus frontalis Zimmermann (Coleoptera: Scolytidae), was studied under field conditions across different seasons. A simple statistical model was then developed to characterize the emergence data, using the truncated geometric distribution. Data are also presented on the mortality of $T$. dubius eggs at various temperatures and humidities in an effort to explain certain aspects of emergence behaviour.

2 Emergence of $T$. dubius from a given tree usually occurred in several discrete episodes across a two-year period, with most individuals emerging in spring or autumn. Almost no emergence occurred in July and August, which may be an adaptation to avoid high temperature mortality. Emergence patterns appeared similar across seasons, with the time of year serving mainly to shift the pattern through time.

3 Cycles in $D$. frontalis abundance may be the result of delayed density dependence generated by its natural enemy complex. The predator T.dubius is likely to be an important component of this delayed density dependence, because of its lengthy development time and apparent impact on D. frontalis.
\end{abstract}

Keywords Bark beetles, Dendroctonus frontalis, diapause, predators, Thanasimus dubius.

\section{Introduction}

The southern pine beetle, Dendroctonus frontalis Zimmermann (Coleoptera: Scolytidae), is an economically important pest of pine forests in the southern U.S.A. (Price et al. 1992). This native bark beetle is able to attack and kill living trees, typically loblolly (Pinus taeda L.) or shortleaf (Pinus echinata Mill.) pine, through a process of mass attack coordinated by aggregation pheromones (Payne, 1980). During this process thousands of beetles bore through the outer bark of the tree and begin constructing galleries in the phloem layer. Oleoresin is released by the tree in response to this activity, but the large number of simultaneous attacks usually exhausts this defence. Oviposition and brood development then occur in the girdled (and ultimately dead) tree. Once a tree is fully colonized, the attack process typically shifts to adjacent trees in the stand, the result being a cluster of freshly attacked trees, trees containing brood, and dead and vacated trees (Coulson, 1980). Mass attack and brood development occur more or less continuously throughout the year in the southern

Correspondence: John D. Reeve. Tel: +1318 4737202; e-mail: jdreeve@attglobal.net
U.S.A., and temperature-driven developmental models indicate that $D$. frontalis can complete about six generations per year (Ungerer et al. 1999). Periodic outbreaks are a prominent feature of $D$. frontalis dynamics in the southern part of its range, with the number of infestations varying by three orders of magnitude between endemic and outbreak periods (Turchin et al. 1991).

A large community of natural enemies is associated with D. frontalis, arriving during mass attack or later on in brood development (Camors \& Payne, 1973; Dixon \& Payne, 1979b). A number of studies indicate that this community can cause significant mortality of $D$. frontalis brood inside the tree (Moore, 1972; Linit \& Stephen, 1983), with the strongest impact occurring in the year following peak $D$. frontalis abundance (Turchin et al., 1999). This delayed density dependence, generated by natural enemies, is a possible explanation for the cyclic nature of $D$. frontalis outbreaks (Turchin et al., 1999; Reeve \& Turchin, 2000). Although these studies have not identified which natural enemies are most responsible for the delayed response, the common predator Thanasimus dubius (F.) (Coleoptera: Cleridae) is a promising candidate. This predator appears to be a significant source of $D$. frontalis mortality (Thatcher \& Pickard, 1966; Tumbow et al., 1978; Reeve, 1997; 
Reeve \& Turchin, 2000), and high densities of $T$. dubius are often associated with declining and low level $\mathbf{D}$. frontalis populations (Billings, 1988; Reeve, 1997; Turchin et al.,1999), as would be expected if they are agents of delayed density dependence. Adult T. dubius arrive almost immediately after mass attack is initiated, attracted by the pheromones of D. frontalis (Vité \& Williamson, 1970; Dixon \& Payne, 1979a). They then prey on the adult $\mathbf{D}$. frontalis arriving on the tree and oviposit in crevices in the bark. The larvae feed on the developing $\mathbf{D}$. j'rontalis brood within the phloem, then enter a non-feeding prepupal stage and construct cells in the outer bark, before emerging as adults (Thatcher \& Pickard, 1966; Mizell \& Nebeker, 1981; Turnbow \& Franklin, 1982).

Given the potential influence of natural enemies on D. frontalis dynamics, it becomes critical to examine the life cycles of these organisms under field conditions. A natural enemy with a long life cycle relative to $\mathbf{D}$. frontalis, for example, would provide a simple explanation for the delayed density dependence in this system. Previous studies of $T$. dubius have examined its development in the laboratory at constant temperatures, where it displays a unimodal distribution of emergence times and a life cycle two or three times as long as D. frontalis (Mignot \& Anderson, 1969; Nebeker \& Purser, 1980; Lawson \& Morgan, 1992). However, a preliminary field study found a much more complex pattern of development, including several peaks of emergence, and some individuals emerging nearly 2 years after D. frontalis attack (Reeve et al., 1996). In this paper, I examine in more detail the development of $T$. dubius under field conditions. Emergence behaviour is examined for different seasons of the year, because time of year often influences the developmental decisions of insects (Tauber etal., 1986). A simple statistical model of emergence behaviour is then developed using the truncated geometric distribution, and its predictions compared with the actual pattern of emergence. I also present data on the mortality of T. dubius eggs at various temperatures and humidities, in an effort to explain certain aspects of emergence behaviour, and review similar studies on egg, larval and adult survival. I then compare the pattern seen for $T$. dubius with other species in this family that attack eruptive bark beetles.

\section{Materials and methods}

\section{Sampling the emergence of $T$. dubius}

I used two different methods to sample the emergence of T. dubius from infested trees: (1) field cages attached to the trees, and (2) rearing boxes containing cut logs. Both techniques were used because it was not clear at the onset of the study which method would prove most effective. (For example, field cages may provide more natural conditions but only function as long as the infested tree remains standing.) The field cages were cylindrical enclosures made of fine polyethylene screening, that encircled a section of the bole from approximately $2-3.5 \mathrm{~m}$ in height. To ensure a close fit to the tree, the bark was smoothed at the top and bottom of the cage with a drawknife, a bead of caulk applied to the bark, and the cage pulled tight with a drawstring and sealed with duct tape. The bottom of each cage ended in two collecting funnels leading to jars filled with an ethylene glycol (antifreeze) solution. The rearing boxes were rectangular wooden enclosures $(121$ X 56 X $56 \mathrm{~cm})$ with three sides made of screening, and a large collecting funnel at the bottom. The boxes were located in shaded locations adjacent to a laboratory building. Both methods of sampling appeared to yield equivalent results, although the field cages sometimes had to be abandoned when the infested trees were felled by decay and high winds.

I sampled a total of nine beetle infestations from 1994 to 1996 (designated C-K) in the Kisatchie and Sabine National Forests, located in central Louisiana and east Texas. An effort was made to sample infestations in each of the four seasons of the year, because this factor could potentially affect the emergence patterns. The infestations were classified as winter, spring, summer, or autumn infestations by the date of $\mathbf{D}$. frontalis emergence from the trees, which was determined by periodic checking of the brood within the trees. It was not possible in most cases to determine the exact date of initial D. frontalis attack, because the infestations were often undetected at that point. However, attack probably occurred 2-3months before $\mathbf{D}$. frontalis emergence in winter trees, 1-2 months before in spring trees, and only one month before in summer trees. Within each infestation, trees were examined until a maximum of four trees were found from which $\mathbf{D}$. frontalis had recently emerged, ranging from 15 to $40 \mathrm{~cm}$ in diameter at breast height. Field cages were then attached to one or two trees in each infestation selected at random. The remaining one or two trees were felled and three $1 \mathrm{~m}$ logs removed from each tree and placed in rearing boxes. Both rearing boxes and field cages were checked every 1-2 weeks for emerging $T$. dubius adults, and any larvae that had fallen into the collecting jars. Preliminary data from infestations $\mathrm{C}-\mathrm{F}$ indicated that no emergence occurred more than 2 years after sampling was begun, so later infestations were sampled no longer than this period. Sampling was also terminated if the tree fell or if no individuals had emerged for a year. Trees with less than 10 emerging T. dubius adults were excluded from subsequent analyses. This left a total of eight winter trees in three infestations $(\mathrm{C}, \mathrm{K}$ and $\mathrm{J})$, four spring trees in two infestations ( $D$ and $H$ ), and six summer trees in three infestations (E, F, I). The density of T. dubius in each tree was estimated by dividing the total number emerged by the surface area trapped. Densities were calculated for only those trees where emergence was judged to be complete, which eliminated a number of caged trees that fell early in the sampling. Data from two trees in infestation $\mathrm{C}$ have been published previously (Reeve etal., 1996).

\section{Distribution of emergence times}

Preliminary analysis of the data suggested that emergence occurs in several distinct episodes for a given tree, with most occurring in either spring or autumn. The number emerging per episode also typically decreased through time. A tree might therefore have a large emergence peak in the spring of the first year of sampling, a smaller one that autumn, and smaller yet peaks in the spring and autumn of the second year of sampling. This pattern suggests that the emergence data follow a geometric distribution, with a probability $s$ that emergence occurs in each successive spring or autumn. To test this hypothesis, I first converted the data into a form suitable for fitting the distribution. For each tree, 
I divided the year into 6-month intervals encompassing spring and autumn, i.e. January-June and July-December, then summed the number emerging in each interval. This yielded a maximum of four numbers for each tree, as sampling was continued for no more than 2 years. I then fitted the truncated geometric distribution to the data, for which the probability of emerging in the $x$ th interval is given by the equation

$$
P[X=x]=\frac{s(1-s)^{x-1}}{\sum_{j=1}^{m} s(1-s)^{j-1}} x=1,2, \ldots, m,
$$

where $m$ is the maximum number of intervals sampled (Mood etal., 1974). The truncated geometric was used because sampling was truncated either by design or naturally when the tree fell. The parameters gives an indication of the overall shape of the distribution, with values near one indicating that most individuals emerge in one episode, whereas small values imply emergence was distributed over several. Maximum likelihood estimates of $s$ were obtained using the module MAXLIK in the GAUSS language (Aptech Systems Inc., 1992). For eight of the trees there were sufficient data for a $\chi^{2}$ goodness-of-fit test to the truncated geometric distribution. One-way ANOVA was used to examine the effect of season on the value of $s$ using systat 9 (SPSS Inc., 1999). In addition, the frequency of male and female $T$. dubius in the first emergence interval vs. all later ones was compared using Fisher's exact test.

\section{Survivorship of $T$. dubius eggs under different environmental regimens}

A growth chamber was used to examine the effects of temperature and humidity on the survival of T.dubius eggs. The eggs were obtained from the third and fourth generation of a laboratory culture of $T$. dubius, initiated from approximately 30 wild individuals collected in the Kisatchie National Forest. This culture was maintained using an artificial diet (J. D. Reeve, M. G. Rojas, and J. A. Morales, unpublished data) for T. dubius larvae, whereas the adult beetles were fed adult Callosobruchus maculatus (F.) (Coleoptera: Bruchidae) (Nebeker et al., 1980). Eggs were collected from the culture three times per week, and the most recently laid eggs (which were translucent in appearance) separated for use in the experiment. Batches of about 200 eggs were then reared at one of six different temperatures $\left(15,20,25,30,35\right.$ and $\left.37.5{ }^{\circ} \mathrm{C}\right)$, with the sequence of the temperature treatments chosen at random. The batch was subdivided into three roughly equal groups and distributed among dessicators where the relative humidity was maintained at $55 \%$ or $76 \%$ using saturated salt solutions $\left(\mathrm{Ca}\left(\mathrm{NO}_{3}\right)_{2}\right.$ or $\mathrm{NaCl}$ ), or near $100 \%$ with water alone (Peterson, 1964). The experiment thus had a total of 18 treatments, six temperatures crossed with three humidities. The eggs were observed daily and the number of hatched larvae recorded. The number of dead eggs was then calculated as the initial number of eggs minus the number of hatched larvae.

I used logistic regression to examine the effect of temperature and humidity on egg mortality (Hosmer \& Lemeshow, 1989). Preliminary analyses showed that temperature had a very strong effect on egg mortality above $30^{\circ} \mathrm{C}$, but it was relatively constant below this temperature. To incorporate this effect in the regression, a transformed temperature variable was constructed that was equal to (T- 30$)^{4}$ above 30 " $\mathrm{C}$, where $T$ is temperature, and equal to zero below $30{ }^{\circ} \mathrm{C}$. This term provided the best fit to the data compared with lower or higher powers in the transformation. There were some cells with zero counts in the data set, because total mortality occurred at 37.5 " $\mathrm{C}$. To deal with this problem, a small constant, $1 \times 10^{-6}$, was added to the counts for all cells. The value of the constant was determined in a sensitivity analysis, in which progressively smaller constants were used until the parameter estimates and goodness-of-fit statistics became stable (Agresti, 1990). The analyses were run using the logistic regression procedure in sYSTAт (SPSS Inc., 1999).

\section{Results}

Typical emergence patterns are shown in Fig. 1, for trees where sampling was initiated in the winter, spring, or summer, just after D. frontalis emergence. Nearly all trees had at least two and some as many as four different emergence episodes, centred around spring and autumn, with some individuals emerging during the second year of sampling. The first emergence episode was in general the largest. Only a few individuals emerged in the summer months of July and August, and emergence in summer trees (Fig. 1C) was apparently delayed until autumn. Male and female emergence appeared to be equally distributed over time. Small numbers of $T$.dubius larvae were often trapped at the beginning of sampling, usually preceding but sometimes overlapping the first emergence episode, but were never trapped after this time.

Estimates of $s$ and other statistics are given in Table 1. All but one tree had a value of $s$ less than one, while the mean development time was greater than one. Both results reflect the fact that emergence occurred in two or more episodes per tree. The value of $s$ provided a useful overall characterization of the emergence pattern, with smaller values of $s$ indicating a greater fraction of individuals undergoing delayed development. However, the truncated geometric distribution failed to fit the data (the $\chi^{2}$ goodness-of-fit test was significant) in four of eight possible cases (Table 1). This result probably indicates a more complex pattern of development (at least in some trees) than can be described by this simple distribution. One-way ANOVA revealed a marginally significant effect of season on $s$ $\left(F_{2,15}=4.308, P=0.033\right)$, with the smallest values ofp occurring in winter trees $(\bar{s}=0.528 \pm 0.113)$, followed by spring $(\bar{s}=0.667 \pm 0.033)$ and then summer $(\bar{s}=0.890 \pm 0.040)$. Averaging across all trees, the mean density of emerging adults was $0.279 \pm 0.053$ per $100 \mathrm{~cm}^{2}$. Sex ratio did not differ significantly between the first emergence episode vs. later episodes (Table 1).

Egg mortality was strongly influenced by temperature above $30^{\circ} \mathrm{C}$ but was relatively constant below this temperature (Fig. 2A). The mortality rate was approximately $20 \%$ at or below $30{ }^{\circ} \mathrm{C}$, increasing to $50 \%$ at $35^{\circ} \mathrm{C}$ and $100 \%$ at $37.5{ }^{\circ} \mathrm{C}$. The temperature term in the logistic regression analysis was highly significant, whereas the humidity terms were nonsignificant (Table 2). 
A. Winter

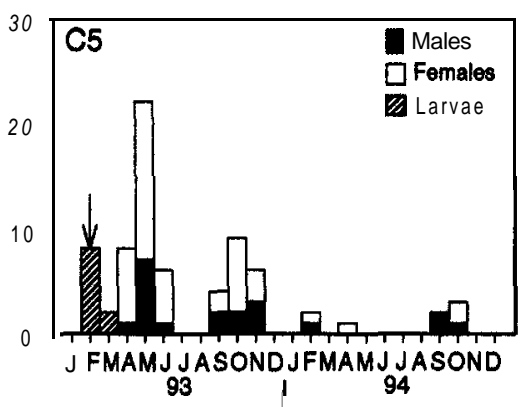

B. Spring

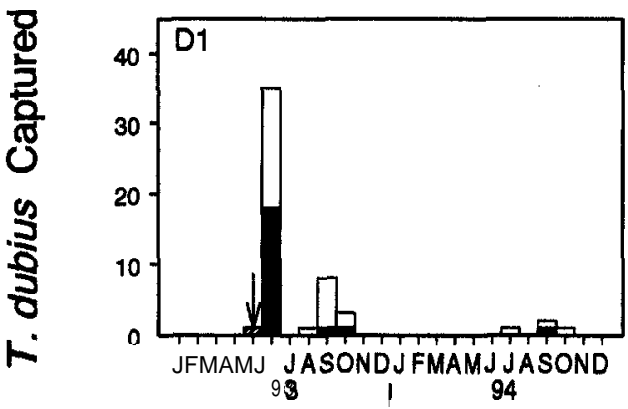

\section{Summer}

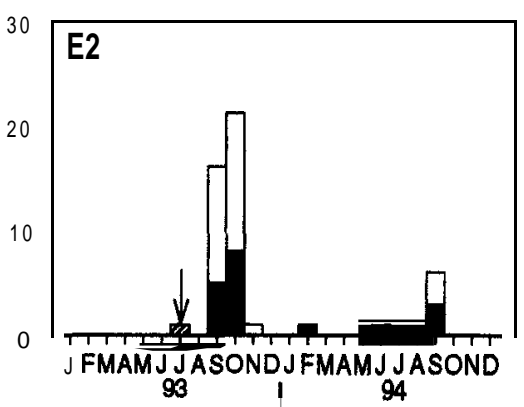

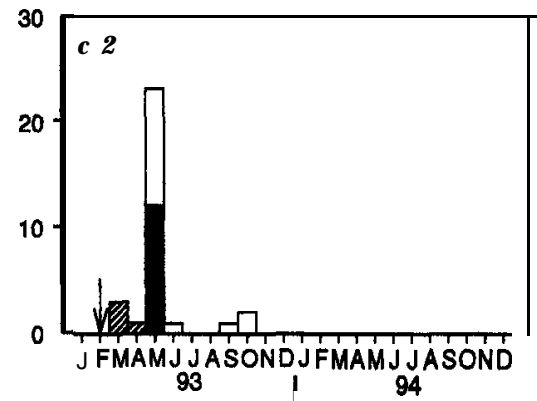
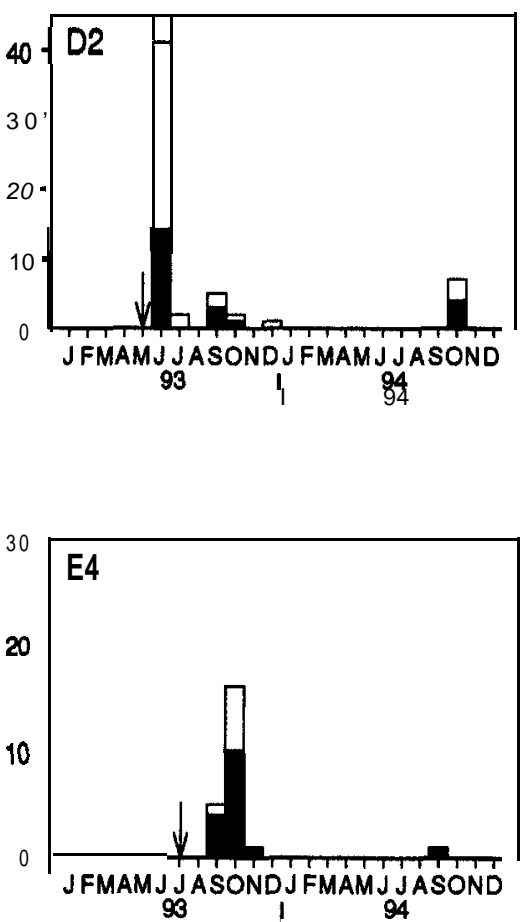

\section{Date}

Figure1 Examples of T. dubius emergence for trees where sampling was initiated in the winter (A), spring (B), or summer (C). An arrow indicates the first sampling date. Trees are identified in the upper right-hand corner of each graph using the same designations as Table 1.

\section{Discussion}

Emergence behaviour for T. dubius was complex and heterogeneous. Emergence generally occurred in several different episodes distributed across a 2-year period, with the bulk of the emergence in spring and autumn. The first emergence episode for a given tree roughly coincides with the development time found in laboratory studies at constant temperatures (Nebeker \& Purser, 1980; Lawson \& Morgan, 1992). For those emerging after the first peak there are two likely explanations: (1) some individuals undergo a period of diapause (Tauber et al.,1986), probably as prepupae in their cells in the outer bark, or (2) some larvae take considerably longer to develop, perhaps due to a shortage of prey inside the tree. The second explanation seems less probable given the pattern observed for $T$. dubius larvae (Fig. 1). These larvae are highly active and often travel on the bark surface (Dix \& Franklin, 1977) and if present would have been trapped by either sampling method. The fact that they were only captured before the first episode suggests that a period of diapause is the most likely explanation for these emergence patterns. However, some variability in larval development times could help explain why certain individuals underwent diapause 
Table1 Maximum likelihood estimates of $s$ and $\chi^{2}$ goodness-of-fit tests for the truncated geometric distribution. Also shown are the total number ( $n$ ) and density of $T$. dubius emerged (number per $100 \mathrm{~cm}^{2}$ of surface area). The mean development time was calculated as the mean number of 6 -month intervals taken to emerge. Fisher's exact test is used to compare the frequency of male and female $T$. dubius in the first emergence interval vs. all later ones combined.

\begin{tabular}{|c|c|c|c|c|c|c|c|c|c|c|c|}
\hline Season & Tree & Cage/Cut & $n$ & $\begin{array}{l}\text { Intervals } \\
\text { sampled* }\end{array}$ & $S$ & $\chi^{2}$ & d.f. & $P$ & $\begin{array}{l}\text { Mean } \\
\text { devel. time }\end{array}$ & $\begin{array}{l}\text { Number per } \\
100 \mathrm{~cm}^{2}\end{array}$ & $\begin{array}{l}\text { Fisher's } \\
\text { exact test }\end{array}$ \\
\hline \multirow[t]{8}{*}{ Winter } & $\mathrm{Cl}$ & Cut & 43 & 4 & 0.935 & & & & 1.070 & 0.219 & ns \\
\hline & $\mathrm{c} 2$ & Cut & 27 & 4 & 0.900 & & - & & 1.111 & 0.277 & ns \\
\hline & c5 & Cage & 63 & 4 & 0.557 & 3.976 & 2 & ns & 1.635 & 0.495 & ns \\
\hline & C6 & Cage & 102 & 4 & 0.314 & 26.810 & 2 & $<0.001$ & 2.039 & 0.772 & ns \\
\hline & $\mathrm{K} 1$ & cut & 68 & 4 & 0.637 & 8.005 & 2 & $<0.025$ & 1.500 & 0.315 & ns \\
\hline & K2 & Cage & 22 & 2 & $0 \dagger$ & & & & 1.772 & & ns \\
\hline & K3 & Cage & 29 & 4 & 0.257 & 22.464 & 2 & $<0.001$ & 2.138 & 0.269 & $\mathrm{~ns}$ \\
\hline & J1 & Cage & 17 & 4 & 0.619 & 0.263 & 1 & ns & 1.529 & 0.110 & $\mathrm{~ns}$ \\
\hline \multirow[t]{4}{*}{ Spring } & $\mathrm{D} 1$ & cut & 51 & 4 & 0.661 & 0.278 & 1 & ns & 1.451 & 0.277 & 0.035 \\
\hline & D2 & Cage & 58 & 4 & 0.616 & 1.732 & 1 & ns & 1.534 & 0.325 & ns \\
\hline & $\mathrm{HI}$ & Cage & 11 & 2 & 0.625 & & & & 1.273 & & ns \\
\hline & $\mathrm{H} 2$ & Cage & 10 & 4 & 0.762 & & & & 1.300 & 0.048 & ns \\
\hline \multirow[t]{6}{*}{ Summer } & El & Cage & 20 & 2 & 0.947 & - & - & & 1.050 & & $\mathrm{~ns}$ \\
\hline & E2 & cut & 46 & 4 & 0.759 & 9.934 & 1 & $<0.005$ & 1.304 & 0.275 & ns \\
\hline & E3 & Cage & 11 & 2 & 0.778 & & - & - & 1.182 & & $\mathrm{~ns}$ \\
\hline & $\mathrm{E} 4$ & cut & 23 & 4 & 0.920 & & & & 1.087 & 0.165 & $\mathrm{~ns}$ \\
\hline & $\mathrm{F} 4$ & Cage & 16 & 2 & 0.933 & & & & 1.063 & & $\mathrm{~ns}$ \\
\hline & & Cage & 13 & 3 & $1 \ddagger$ & & & & 1.000 & 0.077 & \\
\hline
\end{tabular}

* Total number of B-month intervals sampled.

$S=0$ because more individuals emerged in the second than the first interval

$\ddagger s=1$ because all individuals emerged in the first interval.

while others developed immediately, even within the same tree. As environmental cues indicate the approach of summer and poor conditions for reproduction (see below), slower developing larvae may be more likely to enter diapause and wait for better opportunities (Cohen, 1970; Tauber et al., 1986; Bradford \& Roff, 1993).

Emergence patterns appeared more similar than different across the seasons, with season mainly serving to shift the pattern through time. There was some indication that delayed emergence was more common in winter and spring vs. summer trees, because $\mathrm{s}$ differed significantly across seasons, but every season showed delayed emergence. A more prominent feature of the data was the absence of emergence in July and August (see Fig. 1). This behaviour may have evolved to avoid exposure to high summer temperatures and hence increased mortality. Maximum daily temperatures in July and August fall frequently into a range sufficient to cause high egg mortality (Fig. 2B). Similar results were found by Mignot \& Anderson (1969), who demonstrated that egg, larval and adult mortality increased at high temperatures. By contrast, (Tumbow \& Franklin, 1980) observed little or no egg mortality at temperatures at or below 35 " $\mathrm{C}$, but did find that oviposition rates were sharply reduced at high temperatures. The combined effect of temperature on mortality and oviposition rates would probably generate strong selective pressure for diapause during the summer months. Conversely, under field conditions the overall mortality rate of prepupae in their bark cells is very low (Reeve et al., 1996). In this study, prepupae were exposed to the full seasonal range of temperatures across a 2-year period, and it seems plausible that they are more resistant to temperature extremes than the egg stage.
The geographical distribution of $T$, dubius is very broad, apparently extending from Wisconsin (Schenk \& Benjamin, 1969) south to Texas and Louisiana (Thatcher \& Pickard, 1966). Across this range of climates one would expect to see a cline in the number of generations per year and the pattern of diapause, as seen in many other insects (Istock, 198 1; Showers, 198 1; Tauber et al., 1986). In Louisiana and Texas, T. dubius could potentially have two generations per year, but with a significant proportion of the population having one generation per year or even one generation every 2 years. It is likely that in more northern populations this mixture would shift toward generation times of one and 2 years. Two other clerid species also display various mixtures of generation times. Thanasimus Zecontei (Wolcott) is a predator of the western pine beetle, Dendroctonus brevicomis Le Conte, in western North America. This predator can complete two generations per year (while its prey completes three), but 5$20 \%$ of the population take a year to complete development (Person, 1940; Berryman, 1970). In northern Europe, Thanasimusformicarius (L.) primarily has one generation every 2 years, but a small fraction of the population is univoltine (Schroeder, 1999).

Why does such a complex pattern of emergence occur in T. dubius, in which some individuals develop immediately whereas others apparently undergo a lengthy diapause? This behaviour could have evolved as a risk-spreading strategy in response to temporal variation in reproductive success. In this scenario, each female produces both diapause and non-diapause offspring, with diapausers being favoured in more variable environments (Cohen, 1966; Ellner, 1985; Ellner, 1987; Hanski, 1988; Hopper, 1999). There is likely to be substantial variation of this type for $T$.dubius because the number of $D$. frontalis 


\section{A. Egg Mortality}

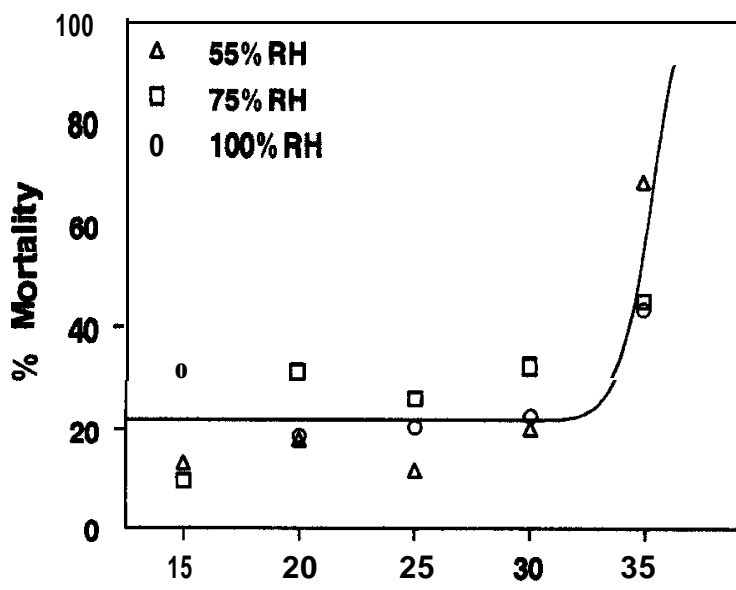

B. Maximum Temperature

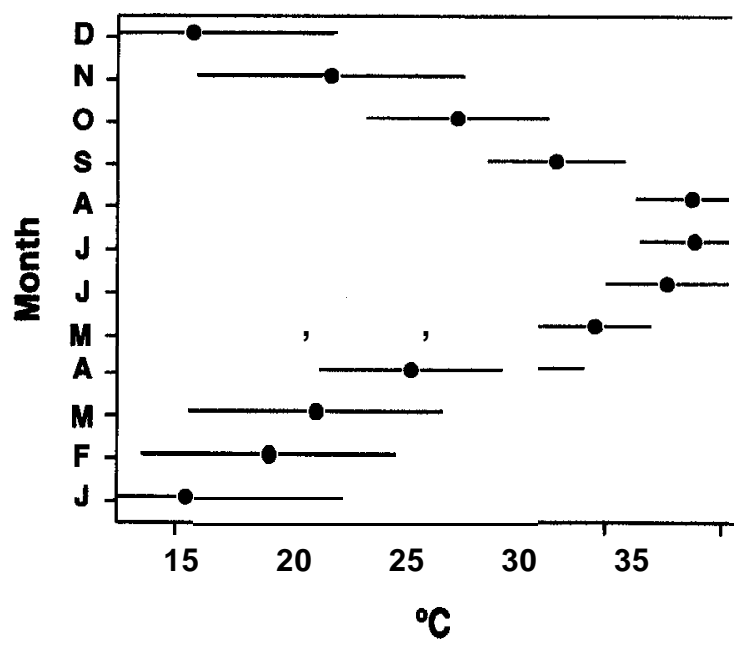

Figure 2 (A) Percent mortality of $T$. dubi us eggs at various temperatures and humidities The fitted curve for the logistic regression model is also shown, averaged across the three humidity treatments. (B) Mean maximum temperatures for the 15" of each month ( \pm SD) from 1930-1993 weather records for Alexandria, Louisiana (National Climatic Data Center, 1995). infestations (and hence prey availability) fluctuates greatly during the outbreak cycle (Turchin etal., 1991). Alternatively, it may be that the pattern observed for T. dubius is a genetic polymorphism in which different genotypes either develop immediately or undergo diapause. The polymorphism would be maintained by a shifting pattern of selection in which the optimal strategy changes from year to year, or by gene flow between populations with different strategies (Hairston \& Dillon, 1990; Bradford \& Roff, 1993). Studies of diapause behaviour at the individual level, including the heritability of diapause, would be necessary to resolve this question (Bradford \& Roff, 1993; Hopper, 1999).

Given the results presented here, it seems likely that $T$. dubius is a component of the delayed response seen in the natural enemy community (Turchin et al., 1999). This predator could at best complete two generations per year, whereas $\mathbf{D}$. frontalis has the potential for six generations (Ungerer etal., 1999), and the occurrence of a diapause in some individuals would add further delays to its numerical response. A simple predator-prey model that incorporates these features, including spring and autumn episodes of emergence and periods of diapause, generates delayed density dependence and cycles similar in period and amplitude to those known for D. frontalis (Reeve \& Turchin, 2000). A possible complicating factor in this system is the existence of alternative prey for $T$. dubius, in particular three species of Ips (I. avulsus, I. calligraphus and I. grandicollis) that attack southern pines (Hopping, 1964, 1965). Unlike D. frontalis, which can become exceedingly rare between outbreaks, trapping data suggest Ips may always be available as prey (J. D. Reeve, unpublished data). Ips are probably not the preferred prey for $\mathbf{T}$. dubius, because they appear much more attracted to D. frontalis than Ips pheromones (Billings \& Cameron, 1984; Billings, 198.5). However, these alternative prey may provide a resource base for $T$. dubius when $D$. frontalis are scarce, and so set a lower limit to predator density. Alternative prey also raise the intriguing possibility of switching behaviour (Murdoch, 1975), with $T$. dubius changing its preference for the different prey species in response to fluctuations in $\mathbf{D}$. frontalis abundance (Billings \& Cameron, 1984; Mizell et al., 1984). Studies by the author and collaborators are further evaluating these factors and their effects on $\boldsymbol{D}$. frontalis dynamics.

Table2 Logistic regression analysis of the effect of temperature and humidity on egg mortality, Humidity was treated as a categorical and temperature as a continuous variable in the analysis. The overall model was highly significant as compared to a model including only a constant $\left(\chi^{2}=466.3\right.$, d. $f$. $=3$, $\left.P<10^{-15}\right)$

\begin{tabular}{|c|c|c|c|c|c|}
\hline Variable & Estimate & Odds Ratio & SE & t-ratio & $\mathbf{P}$ \\
\hline $\begin{array}{l}\text { Constant } \\
\text { Humidity }\end{array}$ & - 1.3049 & & 0.0739 & -17.664 & $<10^{-15}$ \\
\hline $55 \%$ & -0.0826 & 0.9207 & 0.0941 & -0.878 & 0.380 \\
\hline $75 \%$ & 0.0476 & 1. 0487 & 0.0912 & 0.521 & 0.602 \\
\hline Transformed temperature* & 0.0023 & 1. 0023 & 0.0002 & 10.349 & $<10^{-15}$ \\
\hline
\end{tabular}

\footnotetext{
* See formula in Materials and Methods,
} 


\section{Acknowledgements}

I thank Jonny S. Fryar and John A. Simpson for the design of the field cages and the endless hours spent travelling to the study sites. James T. Cronin, Kier D. Klepzig, Kenneth F. Raffa, Brian L. Strom and two anonymous reviewers provided very useful comments on the manuscript.

\section{References}

Agresti, A. (1990) Categorical Data Analysis. John Wiley \& Sons Inc, New York.

Aptech Systems Inc. (1992) The GAUSS System, Version 3.0. Aptech Systems Inc., Maple Valley, WA.

Berryman, A.A. (1970) Evaluation of insect predators of the western pine beetle. Studies on the Population Dynamics of the Western Pine Beetle, Dendroctonus brevicomis leconte (Coleoptera: Scolytidue) (ed. by R. W. Stark and D. L. Dahlsten), pp. 102-1 12. University of California, Division of Agricultural Sciences, Berkeley, CA.

Billings, R.F. (1985) Southern pine bark beetles and associated insects: effects of rapidly-released host volatiles on response to aggregation pheromones. Zeitschrift für Angewandt Entomologie, 99, 483-491.

Billings, R.F. (1988) Forecasting southern pine beetle infestation trends with pheromone traps. Integrated Control of Scolytid Bark Beetles (ed. by T. L. Payne and H. Sarenmaa), pp. 295-306. Virginia Polytechnic Institute and State University, Blacksburg, VA.

Billings, R.F. \& Cameron, R.S. (1984) Kairomonal responses of Coleoptera, Monochamus titillator (Cerambycidae), Thanasimus dubius (Cleridae), and Temnochila virescens (Trogositidae), to behavioral chemicals of southern pine bark beetles (Coleoptera: Scolytidae). Environmental Entomology, 13, 1542-1548.

Bradford, M.J. \& Roff, D.A. (1993) Bet hedging and the diapause strategies of the cricket Allonemobius fasciatus. Ecology, 74, 1129-1135.

Camors, F.B. \& Payne, T.L. (1973) Sequence of arrival of entomophagous insects to trees infested with southern pine beetle. Environmental Entomology, 2, 267-270.

Cohen, D. (1966) Optimizing reproduction in a randomly varying environment. Journal of Theoretical Biology, 12, 119-129.

Cohen, D. (1970) A theoretical model for the optimal timing of diapause. American Naturalist, 104, 389-400.

Coulson, R.N. (1980) Population dynamics. The Southern Pine Beetle (ed. by R. C. Thatcher, J. L. Searcy, J. E. Coster and G. D. Hertel), pp. 70-105. USDA Forest Service Technical Bulletin 1631.

Dix, M.E. \& Franklin, R.T. (1977) Diel activity of Thanasimus dubius, a southern pine beetle predator. Journal of the Georgia Entomological Society, 12, 71-75.

Dixon, W.N. \& Payne, T.L. (1979a) Sequence of Arrival and Spatial Distribution of Entomophagous and Associate Insects on Southern Pine Beetle-Infested Trees. Texas Agricultural Experiment Station Miscellaneous Publication 1432. College Station, Texas.

Dixon, W.N. \& Payne, T.L. (1979b) Aggregation of Thanasimus dubius on trees under mass-attack by the southern pine beetle. Environmental Entomology, 8, 178-181.

Ellner, S. (1985) ESS germination strategies in randomly varying environments. I. Logistic-type models. Theoretical Population Biology, 28, 50-79.

Ellner, S. (1987) Competition and dormancy: a reanalysis and review. American Naturalist, $\quad \mathbf{1 3 0}, \quad \mathbf{7 9 8 - 8 0 3 .}$

Hairston, N.G. \& Dillon, T.A. (1990) Fluctuating selection and response in a population of freshwater copepods. Evolution, 44, 1796-1805.
Hanski, I. (1988) Four kinds of extra long diapause in insects: a review of theory and observations. Annales Zoologici Fennici, 25, 37-53.

Hopper, K.R. (1999) Risk-spreading and bet-hedging in insect population biology. Annual Review of Entomology, 44, 535-560.

Hopping, G.R. (1964) The North American species in group IV and V of Ips De Geer (Coleoptera: Scolytidae). Canadian Entomologist, 96, 970-978.

Hopping, G.R. (1965) The North American species in group X of Ips De Geer (Coleoptera: Scolytidae). Canadian Entomologist, 97, 803-809.

Hosmer, D.W. \& Lemeshow, S. (1989) Applied Logisticrregression. John Wiley \& Sons Inc, New York.

Istock, C.A. (1981) Natural selection and life history variation: theory plus lesson from a mosquito. Insect Life History Patterns (ed. by R. F. Denno and H. Dingle), pp. 113-127. Springer-Verlag, New York.

Lawson, S.A. \& Morgan, F.D. (1992) Rearing of two predators, Thanasimus dubius and Temnochila virescens, for the biological control of Ips grandicollis in Australia. Entomologia Experimentalis et Applicata, 65, 225-233.

Linit, M.J. \& Stephen, F.M. (1983) Parasite and predator components of within-tree southern pine beetle (Coleoptera: Scolytidae) mortality. Canadian Entomologist, 115, 679-688.

Mignot, E.C. \& Anderson, R.F. (1969) Bionomics of the bark beetle predator, Thanasimus dubius Fab. (Coleoptera: Cleridae). Entomological News, 80, 305-310.

Mizell,R.F., IIIFrazier, J.L. \& Nebeker, T.E. (1984) Response of the clerid predator Thanasimus dubius (F.) to bark beetle pheromones and tree volatiles in a wind tunnel. Journal of Chemical Ecology, 10, 177-187.

Mizell,R.F. III \& Nebeker, T.E. (1981) Within-tree distribution of the pupae of Thanasimus dubius (Coleoptera: Cleridae), a predator of the southern pine beetle (Coleoptera: Scolytidae). Canadian Entomologist, 113, 387-394.

Mood, A.M., Graybill, F.A. \& Boes, D.C. (1974). Introduction to the Theory of Statistics. 3rd edn. McGraw-Hill Inc, New York.

Moore, G.E. (1972) Southern pine beetle mortality in North Carolina caused by parasites and predators. Environmental Entomology, 1, $58-65$.

Murdoch, W.W. (1975) Diversity, complexity, stability and pest control. Journal of Applied Ecology, 12, 795-807.

National Climatic Data Center (1995) Cooperative Summary of the Day, 14. National Climatic Data Center, Asheville, NC.

Nebeker, T.E. \& Purser, G.C. (1980) Relationship of temperature and prey type to development time of the bark beetle predator Thanasimus dubius (Coleoptera: Scolytidae). Canadian Entomologist, $\quad \mathbf{1 1 2}, \quad 179-184$.

Nebeker, T.E., Purser, G.C. \& Mizell,R.F. III (1980) Collection and maintenance of Thanasimus dubius (F.) for biological and behavioral studies. Journal of the Georgia Entomological Society, 15, 406-412.

Payne, T.L. (1980) Life history and habits. The Southern Pine Beetle (ed. by R. C. Thatcher, J. L. Searcy, J. E. Coster and G. D. Hertel), pp. 7-28. USDA Forest Service Technical Bulletin 1631.

Person, H.L. (1940) The clerid Thanasimus lecontei (Wolc.) as a factor in the control of western pine beetle. Journal of Forestry, 38, 390-396.

Peterson, A. (1964) Entomological Techniques: How to Work with Insects. Edwards Brothers Inc, Ann Arbor, MI.

Price, T.S., Doggett, C., Pye, J.M. \& Holmes, T.P. (1992) A History of Southern Pine Beetle Outbreaks in the Southeastern United States. Georgia Forestry Commission, Macon, GA.

Reeve, J.D. (1997) Predation and bark beetle dynamics. Oecologia, 112, 48.54.

Reeve, J.D., Simpson, J.A. \& Fryar, J.S. (1996) Extended development 
in Thanasimus dubius (F.) (Coleoptera: Cleridae), a predator of the southern pine beetle. Journal of Entomological Science, 31, 123-131.

Reeve, J.D. \& Turchin, P. (2000) Evidence for predator-prey cycles in a bark beetle. Population Cycles: Evidence for Trophic Interactions (ed. by A. A. Berryman). Oxford University Press. New York, in press.

Schenk, J.A. \& Benjamin, D.M. (1969) Notes on the biology of Ipspini in central Wisconsin jack pine forests. Annals of the Entomological Society of America, 62, 480-485.

Schroeder, L.M. (1999) Prolonged development time of the bark beetle predator Thanasimus formicarius (Col. Cleridae) in relation to its prey species Tomicus piniperda (L.) and Z ps typographus (L.) (Col. Scolytidae). Agricultural and Forest Entomology, 1, 127-136.

Showers, W.B. (1981) Geographic variation of the diapause response in the european corn borer. Insect Life History Patterns (ed. by R. F. Denno and H. Dingle), pp. 97-111. SpringerVerlag. New York.

SPSS Inc. (1999) systat 9 Statistcs I. SPSS Inc., Chicago, IL. Tauber, M.J., Tauber, C.A. \& Masaki, S. (1986) Seasonal Adaptations of Insects. Oxford University Press, New York.

Thatcher, R.C. \& Pickard, L.S. (1966) The clerid beetle, Thanasimus dubius, as a predator of the southern pine beetle. Journal of Economic Entomology, 59, 955-957.
Turchin, P., Lorio, P.L. Jr, Taylor, A.D. \& Billings, R.F. (1991) Why do populations of southern pine beetles (Coleoptera: Scolytidae) fluctuate? Environmental Entomology, 20, 401-409.

Turchin, P., Taylor, A.D. \& Reeve, J.D. (1999) Dynamical role of predators in population cycles of a forest insect: an experimental test. Science, 285, 1068-1071.

Tumbow, R.H. \& Franklin, R.T. (1980) The effects of temperature on Thanasimus dubius oviposition, egg development and adult prey consumption. Journal of the Georgia Entomological Society, 15, 456-459.

Tumbow, R.H. \& Franklin, R.T. (1982) Behavior and development of an overwintering population of the southern pine beetle predator, Thanasimus dubius (Fab.). Journal of the Georgia Entomological Society, $17,292 \cdot 297$.

Tumbow, R.H., Franklin, R.T. \& Nagel, W.P. (1978) Prey consumption and longevity of adult Thanasimus dubius. Environmental Entomology, 7, 695.697.

Ungerer, M.J., Ayres, M.P. \& Lombardero, M.J. (1999) Climate and the northern distribution limits of Dendroctonus frontalis Zimmermann (Coleoptera: Scolytidae). Journal of Biogeography, 26, 1133-1145

Vité, J.P. \& Williamson, D.L. (1970) Thanasimus dubius: prey perception, Journal of Insect Physiology, 106, 233-239.

Accepted 26 June 2000 